Article

\title{
Thermodynamic Analysis of the V-Shaped Area of High Pressure and High Temperature in Cubic Boron Nitride Synthesis with $\mathrm{Li}_{3} \mathrm{~N}$ as a Catalyst
}

\section{Bin Xu *, Mei-Zhe Lv, Hong-Mei Yang and Zhen-Xing Wen}

School of Materials Science and Engineering, Shandong Jianzhu University, Jinan 250101, China; E-Mails: 1vmeizhe@163.com (M.-Z.L.); yhme327@163.com (H.-M.Y.);wzxsyz@163.com (Z.-X.W.)

* Author to whom correspondence should be addressed; E-Mail: xubin@sdjzu.edu.cn; Tel.: +86-531-8636-7283; Fax: +86-531-8636-7282.

Received: 4 December 2013; in revised form: 22 January 2014 / Accepted: 7 February 2014 / Published: 14 February 2014

\begin{abstract}
The possibilities of different phase transitions to $\mathrm{cBN}$ with $\mathrm{Li}_{3} \mathrm{~N}$ as catalyst at high temperature and high pressure $(1600-2200 \mathrm{~K}, 4.8-6.0 \mathrm{GPa})$ are analyzed, in the framework of the second law of thermodynamics. The Gibbs free energy $(\Delta G)$ of three reactions which may happen in the $\mathrm{Li}_{3} \mathrm{~N}-\mathrm{BN}$ system: $\mathrm{hBN}+\mathrm{Li}_{3} \mathrm{~N} \rightarrow \mathrm{Li}_{3} \mathrm{BN}_{2}, \mathrm{hBN} \rightarrow \mathrm{cBN}$, and $\mathrm{Li}_{3} \mathrm{BN}_{2} \rightarrow \mathrm{cBN}+\mathrm{Li}_{3} \mathrm{~N}$, is calculated, with the influence of high temperature and high pressure on volume included. We show that $\Delta G$ of $\mathrm{hBN}+\mathrm{Li}_{3} \mathrm{~N} \rightarrow \mathrm{Li}_{3} \mathrm{BN}_{2}$ and $\mathrm{hBN} \rightarrow \mathrm{cBN}$ are between $-35 \sim-10 \mathrm{KJ} \cdot \mathrm{mol}^{-1}$ and $-25 \sim-19 \mathrm{KJ} \cdot \mathrm{mol}^{-1}$, respectively. However, $\Delta G$ of $\mathrm{Li}_{3} \mathrm{BN}_{2} \rightarrow \mathrm{cBN}+\mathrm{Li}_{3} \mathrm{~N}$ can be positive or negative. The area formed by the positive data is a $\mathrm{V}$-shaped area, which covers the most part of the cBN growing V-shaped area. It confirms that $\mathrm{Li}_{3} \mathrm{BN}_{2}$ is stable in the P-T area of $\mathrm{cBN}$ synthesis, and $\mathrm{cBN}$ is probably transformed directly from $\mathrm{hBN}$. Analysis suggests that $\mathrm{Li}_{3} \mathrm{BN}_{2}$ promotes the transition from $\mathrm{hBN}$ to $\mathrm{cBN}$.
\end{abstract}

Keywords: cBN single crystal; high pressure and high temperature; V-shaped area; thermodynamic analysis; Gibbs free energy

PACS Codes: $64.10 .+\mathrm{h}$ 


\section{Introduction}

High static pressure is the most common method to synthesize cubic boron nitride (cBN) with hexagonal boron nitride (hBN) as raw material and with alkaline metals or alkaline-earth metals and their nitrides as catalysts. The cBN synthesized with lithium nitride $\left(\mathrm{Li}_{3} \mathrm{~N}\right)$ is widely used because of its regular crystal shape and suitable particle size. A layer of white powder covers the surface of cBN crystal during the growth. Phase structure characterizations show that the layer is composed of $\mathrm{hBN}$, micro $\mathrm{cBN}$ and lithium boron nitrides $\left(\mathrm{Li}_{3} \mathrm{BN}_{2}\right)$ [1]. It is very desirable to study their relationships to understand the phase transition mechanism of $\mathrm{cBN}$ as they are in direct contact with the cBN single crystals.

Previous studies indicate that no matter what kind of catalyst is adopted, the temperature and pressure forms a V-shaped area [2-4] where cBN can grow stably. Besides there is a short-range ordered or medium-range ordered structure in high temperature and high pressure (HPHT) system [5], namely a solid microstructure existing in the HPHT system. It was proposed that $\mathrm{cBN}$ was directly transformed from $\mathrm{hBN}$ [6], while [7] believed that $\mathrm{cBN}$ was precipitated from solvent. Thermodynamic analysis plays an important role in understanding the synthesis mechanism of diamond [8,9]. Therefore it is possible to investigate the phase transition mechanism of $\mathrm{cBN}$ because of the similar structure. However, there are few reports about the thermodynamics of the cBN transition mechanism with catalyst at HPHT due to the absence of thermodynamic data at HPHT and the ambiguity of the mechanism. Bocquillon et al. $[3,10]$ put forward the following reactions in the $\mathrm{Li}_{3} \mathrm{~N}-\mathrm{hBN}$ system:

$$
\begin{aligned}
& \mathrm{Li}_{3} \mathrm{~N}+\mathrm{hBN} \rightarrow \mathrm{Li}_{3} B N_{2} \\
& \mathrm{Li}_{3} B N_{2} \rightarrow \mathrm{Li}_{3} \mathrm{~N}+\mathrm{cBN}
\end{aligned}
$$

After the reactions, all of the phase are found around the cBN crystals by XRD [1], except for the volatile $\mathrm{Li}_{3} \mathrm{~N}$. It is difficult to identify the reactions through experiments because the online inspection is impractical. The synthesis of $\mathrm{cBN}$ is an isobaric and isothermal process, and we can apply classical thermodynamics to analyze the reactions in the system by querying the related thermodynamic data. Based on the second law of thermodynamics, we calculate the change of Gibbs free energy in (1) and (2) and analyze the thermodynamic transformation of $\mathrm{cBN}$ in $\mathrm{V}$-shaped area of the system.

\section{Calculation}

The calculation is based on the second law of thermodynamics. The change of Gibbs free energy $\Delta G$ is:

$$
G_{T}^{P}=G_{T}^{P}+\int_{P^{\theta}}^{P} V d P
$$

Under the isobaric condition, $\Delta G$ can be obtained:

$$
\Delta G_{T}^{\theta}=\Delta H_{T}^{\theta}-T \Delta S_{T}^{\theta}=\Delta_{f} H^{\theta}+\int_{T_{0}}^{T} \Delta C_{P} d T-T \times\left(\Delta_{r} S^{\theta}+\int_{T_{0}}^{T} \frac{\Delta C_{P}}{T} d T\right)
$$

$\Delta G$ between different temperatures and pressures can be expressed as [11]:

$$
\begin{aligned}
\Delta G_{T}^{P}= & \left(\Delta H_{T}^{0}-T \Delta S_{T}^{0}\right)+\left(\int_{T_{0}}^{T} \Delta C_{P}-T \int_{T 0}^{T} \frac{\Delta C_{P}}{T} d T\right)+ \\
& +\int_{P 0}^{P}\left[\left(V_{0}+\Delta V_{T}+\Delta V_{P}\right)_{\text {Product }}-\left(V_{0}+\Delta V_{T}+\Delta V_{P}\right)_{\text {Reactant }}\right] d P
\end{aligned}
$$


Equation (5) takes the influence of temperature and pressure to volume into consideration. $\Delta H_{T}^{0}$ and $\Delta S_{T}^{0}$ are enthalpy and entropy of crystalline phase in the system, respectively. $V_{0}$ is the mole volume at normal temperature and pressure. $\Delta V_{T}$ and $\Delta V_{P}$ are the variation of mole volume with constant temperature and pressure, respectively. According to $[12,13]$, the related thermodynamic quantities can be acquired. Similarly, we get $\Delta G$ of $\mathrm{Li}_{3} \mathrm{BN}_{2}$ from [14]:

$$
\begin{aligned}
\Delta G^{\theta}\left(T, P^{\theta}\right)= & -425.42206+0.07512 T-1.778 \times 10^{-4} T^{2}+ \\
& +4.144 \times 10^{-8} T^{3}+\frac{27.9}{T}-9.306 \times 10^{-3} T \ln T
\end{aligned}
$$

$298 \mathrm{~K}$ is chosen as the start temperature. $\Delta V_{T}$ and $\Delta V_{P}$ are calculated in the following.

2.1. $\Delta V_{P}$

Based on the state equation of crystal under high pressure by Sung [15], we use the Birch-Murnaghan equation of crystal state to calculate the variation of volume under high pressure:

$$
P=\frac{3}{2}\left(\frac{V_{0}}{V_{0}+\Delta V_{P}}\right)^{\frac{5}{3}}\left[\left(\frac{V_{0}}{V_{0}+\Delta V_{P}}\right)^{\frac{2}{3}}-1\right]\left\{1+\frac{3}{4}\left(B_{0}^{\prime}-4\right)\left[\left(\frac{V_{0}}{V_{0}+\Delta V_{P}}\right)^{\frac{2}{3}}-1\right]\right\}
$$

In Equation (7), $B_{0}$ is bulk modulus, and $B_{0}{ }^{\prime}$ is the first derivative of the pressure with respect to bulk modulus. From Equation (7), the relation between $\Delta V_{P}$ and pressure can be obtained. Table 1 shows the physical parameters of materials in reactions in the $\mathrm{Li}_{3} \mathrm{~N}-\mathrm{BN}$ HPHT system.

Table 1. Physical parameters of the materials participating in the reactions.

\begin{tabular}{cccc}
\hline Material & $\boldsymbol{V}_{\mathbf{0}} / \mathbf{c m}^{\mathbf{3}} \cdot \mathbf{m o l}^{\mathbf{- 1}}$ & $\boldsymbol{B}_{\mathbf{0}} / \mathbf{G P a}$ & $\boldsymbol{B}_{\mathbf{0}}{ }^{\mathbf{G}} \mathbf{G P a}$ \\
\hline $\mathrm{cBN}$ & 7.1150 & $398.6[16]$ & $3.85[16]$ \\
$\mathrm{hBN}$ & 10.8820 & $36.7[17]$ & $5.6[17]$ \\
$\mathrm{Li}_{3} \mathrm{~N}$ & 27.2031 & $98[18]$ & $4.04[18]$ \\
$\mathrm{Li}_{3} \mathrm{BN}_{2}$ & 34.0850 & - & - \\
\hline
\end{tabular}

In Table 1, the $B_{0}$ and $B_{0}{ }^{\prime}$ are not found in references. According to [11], they can be deduced from Vegard's law from the $B_{0}$ and $B_{0}{ }^{\prime}$ of $\mathrm{Li}_{3} \mathrm{~N}$ and cBN:

$$
B_{0}=x_{1} B_{1}+x_{2} B_{2}=B_{L i_{3} N}+B_{c B N}
$$

In Equation (8), $B_{0}$ and $B_{1}$ and $B_{2}$ are the bulk modulus of $\mathrm{Li}_{3} \mathrm{BN}_{2}, \mathrm{Li}_{3} \mathrm{~N}$ and cBN, respectively. $x_{1}$, $x_{2}$ are the percentage of $\mathrm{Li}_{3} \mathrm{~N}$ and $\mathrm{cBN}$, with $x_{2}=1-x_{1} . B_{0}{ }^{\prime}$ could be calculated by the same method. The $B_{0}$ of $\mathrm{Li}_{3} \mathrm{BN}_{2}$ is 248.3 and $B_{0}{ }^{\prime}$ is 3.945 .

\section{2. $\Delta V_{T}$}

$\Delta V_{T}$ can be obtained on the basis of the thermal expansion properties of crystals:

$$
\Delta V_{T}=V_{0} \beta \Delta T=V_{0} \beta\left(T-T_{0}\right)
$$

In Equation (9), $\beta$ refers to the volume expansion coefficient, and its value of $h B N, c B N$ and $\mathrm{Li}_{3} \mathrm{~N}$ can be obtained from $[19,20]$, but there has been no report on the value $\beta$ of $\mathrm{Li}_{3} \mathrm{BN}_{2}$. It can be calculated as follows: 


$$
C_{p}-C_{v}=\frac{V_{0} T \beta^{2}}{\kappa}
$$

where $C_{v}$ is the molar heat capacity at constant volume and $\kappa$ is the isothermal compressibility with $\kappa=1 / B$. According to the definition of bulk modulus, the Equation (10) can be written as

$$
C_{P}-C_{V}=\left(B_{0}+B_{0}^{\prime} \times P\right) V_{0} T \beta^{2}
$$

From [14] $C_{p}$ of $\mathrm{Li}_{3} \mathrm{BN}_{2}$ can be obtained as follows:

$$
C_{P}=9.306+355.6 \times 10^{-3} T-5.58 \times 10^{4} T^{-2}-24.86 \times 10^{-5} T^{2}
$$

and the $\beta$ of $\mathrm{Li}_{3} \mathrm{BN}_{2}$ can thus be calculated:

$$
\beta=1.68324 \times 10^{-4}+1.21253 \times 10^{-8} T-8.96867 \times 10^{-11} T^{2}+1.30857 \times 10^{-14} T^{3}
$$

\section{Results and Discussion}

Different $\mathrm{P}-\mathrm{T}$ areas of $\mathrm{cBN}$ growth in the $\mathrm{Li}_{3} \mathrm{~N}-\mathrm{hBN}$ system [2-4] have been proposed, which may be related to the purity and degree of order of the $\mathrm{hBN}$ and the synthesis process used. The lowest synthesis pressure is $4.8 \mathrm{GPa}$ and the minimum synthesis temperature is $1690 \mathrm{~K}$ at $5.0 \mathrm{GPa}$ in $\mathrm{Li}_{3} \mathrm{~N}-\mathrm{hBN}$ system [4], which approximates the V-shaped area proposed in [3]. Ko [7] found that the lowest temperature was $1620 \mathrm{~K}$ at $5.3 \mathrm{GPa}$, lower than the lowest temperature $(1723 \mathrm{~K})$ reported by Bocquillon [3]. Considering the industrial application and the reliability of the numerical calculation is performed in an expanded region of $1600-2200 \mathrm{~K}$ and $4.8-6.0 \mathrm{GPa}$.

Table 2 shows the change of Gibbs free energy of $\mathrm{Li}_{3} \mathrm{~N}+\mathrm{hBN} \rightarrow \mathrm{Li}_{3} \mathrm{BN}_{2}$ in the HPHT area $(1600-2200 \mathrm{~K}, 4.8-6.0 \mathrm{GPa})$ of cBN synthesis in the $\mathrm{Li}_{3} \mathrm{~N}-\mathrm{hBN}$ system. The values of $\Delta G$ are between -35 and $-10 \mathrm{KJ} \cdot \mathrm{mol}^{-1}$. This illustrates that $\mathrm{Li}_{3} \mathrm{~N}$ can transform into $\mathrm{Li}_{3} \mathrm{BN}_{2}$ in this $\mathrm{P}-\mathrm{T}$ area, in coincidence with the XRD results of the catalyst after synthesis [1].

Table 2. $\Delta G$ of $\mathrm{hBN}+\mathrm{Li}_{3} \mathrm{~N} \rightarrow \mathrm{Li}_{3} \mathrm{BN}_{2}$ at different temperatures and pressures.

\begin{tabular}{cccccccc}
\hline \multirow{2}{*}{$\mathbf{T} / \mathbf{K}$} & \multicolumn{7}{c}{$\Delta \boldsymbol{G} /\left(\mathbf{K J}^{\prime} \mathbf{m o l}^{-1}\right)$} \\
\cline { 2 - 8 } & $\mathbf{4 . 8} \mathbf{~ G P a}$ & $\mathbf{5 . 0 ~ G P a}$ & $\mathbf{5 . 2 ~ G P a}$ & $\mathbf{5 . 4 ~ G P a}$ & $\mathbf{5 . 6} \mathbf{~ G P a}$ & $\mathbf{5 . 8 ~ G P a}$ & $\mathbf{6 . 0 ~ G P a}$ \\
\hline 1600 & -16.4319 & -17.9111 & -19.3804 & -20.8399 & -22.2898 & -23.7301 & -25.1611 \\
1650 & -17.3670 & -18.9879 & -20.5988 & -22.2000 & -23.7916 & -25.3736 & -26.9463 \\
1700 & -18.1161 & -19.8872 & -21.6483 & -23.3996 & -25.1413 & -26.8735 & -28.5963 \\
1750 & -18.6561 & -20.5857 & -22.5054 & -24.4154 & -26.3156 & -28.2064 & -30.0878 \\
1800 & -18.9630 & -21.0597 & -23.1464 & -25.2233 & -27.2905 & -29.3483 & -31.3967 \\
1850 & -19.0122 & -21.2842 & -23.5463 & -25.7985 & -28.0411 & -30.2743 & -32.4980 \\
1900 & -18.7784 & -21.2340 & -23.6797 & -26.1156 & -28.5418 & -30.9586 & -33.3660 \\
1950 & -18.2357 & -20.8831 & -23.5206 & -26.1482 & -28.7663 & -31.3749 & -33.9740 \\
2000 & -17.3573 & -20.2046 & -23.0420 & -25.8696 & -28.6875 & -31.4959 & -34.2951 \\
2050 & -16.1162 & -19.1714 & -22.2166 & -25.2521 & -28.2779 & -31.2942 & -34.3011 \\
2100 & -14.4845 & -17.7554 & -21.0163 & -24.2674 & -27.5089 & -30.7409 & -33.9634 \\
2150 & -12.4339 & -15.9281 & -19.4124 & -22.8869 & -26.3518 & -29.8071 & -33.2531 \\
2200 & -9.9353 & -13.6604 & -17.3756 & -21.0809 & -24.7767 & -28.4629 & -32.1398 \\
\hline
\end{tabular}


$\Delta G$ varies regularly with the increase of temperature and pressure. It decreases firstly and then rises with the increasing temperature under constant pressure. $\Delta G$ decreases monotonically with the increasing pressure when temperature keeps constant. The higher temperature and pressure, the more negative $\Delta G$, it is easier to generate $\mathrm{Li}_{3} \mathrm{BN}_{2}$. The possibility of the reaction exists, although the absolute value of $\Delta G$ is very small.

Table 3 shows $\Delta G$ of transition $\mathrm{hBN}-\mathrm{cBN}$ in HPHT area $(1600-2200 \mathrm{~K}, 4.8-6.0 \mathrm{GPa})$ of cBN synthesis. In consideration of the influence of temperature and pressure on phase volume, relatively precise calculation results are obtained. $\Delta G$ of the transition is between -25 and $-19 \mathrm{KJ} \cdot \mathrm{mol}^{-1} . \Delta G$ is negative and its absolute value increases with the increasing temperature and pressure, and it is more and more probable for the transition to occur. From Table 3, we find that $\Delta G$ changes more sharply with the pressure than with the temperature. Therefore, the transition of $\mathrm{hBN}$ to $\mathrm{cBN}$ is probable in the P-T area, and pressure is greater impact than temperature.

Table 3. $\Delta G$ of $\mathrm{hBN} \rightarrow \mathrm{cBN}$ at different temperatures and pressures.

\begin{tabular}{cccccccc}
\hline \multirow{2}{*}{$\boldsymbol{T} / \mathbf{K}$} & \multicolumn{7}{c}{$\Delta \boldsymbol{G} / \mathbf{K J}^{*} \mathbf{m o l}^{-\mathbf{1}} \mathbf{)}$} \\
\cline { 2 - 8 } 1600 & -19.7724 & -20.4187 & -21.0596 & -21.6952 & -22.3255 & -22.9507 & -23.5707 \\
1650 & -19.7917 & -20.4391 & -21.0810 & -21.7176 & -22.3490 & -22.9752 & -23.5963 \\
1700 & -19.8295 & -20.4774 & -21.1198 & -21.7569 & -22.3887 & -23.0154 & -23.6370 \\
1750 & -19.8857 & -20.5334 & -21.1758 & -21.8127 & -22.4445 & -23.0710 & -23.6925 \\
1800 & -19.9600 & -20.6070 & -21.2485 & -21.8847 & -22.5156 & -23.1414 & -23.7620 \\
1850 & -20.0523 & -20.6977 & -21.3377 & -21.9723 & -22.6016 & -23.2258 & -23.8450 \\
1900 & -20.1622 & -20.8052 & -21.4427 & -22.0750 & -22.7019 & -23.3238 & -23.9405 \\
1950 & -20.2893 & -20.9290 & -21.5633 & -22.1922 & -22.8158 & -23.4343 & -24.0477 \\
2000 & -20.4333 & -21.0687 & -21.6986 & -22.3232 & -22.9425 & -23.5567 & -24.1657 \\
2050 & -20.5936 & -21.2235 & -21.8480 & -22.4672 & -23.0811 & -23.6898 & -24.2935 \\
2100 & -20.7697 & -21.3930 & -22.0109 & -22.6234 & -23.2307 & -23.8328 & -24.4299 \\
2150 & -20.9609 & -21.5763 & -22.1863 & -22.7909 & -23.3903 & -23.9845 & -24.5736 \\
2200 & -21.1665 & -21.7726 & -22.3733 & -22.9686 & -23.5587 & -24.1436 & -24.7235 \\
\hline
\end{tabular}

We show the results in Table 4 supposing that $\mathrm{Li}_{3} \mathrm{BN}_{2}$ could decompose into $\mathrm{cBN}$. We find that when the pressure is as low as $4.8 \mathrm{GPa}, \Delta G$ is negative and $\Delta G$ increases from negative to positive with increasing temperature and pressure. $\Delta G$ increases from negative to positive with increasing pressure when the temperature is constant. However, $\Delta G$ increases first and then decreases with the increasing temperature under constant pressure, and $\Delta G$ of reaction $\mathrm{Li}_{3} \mathrm{BN}_{2} \rightarrow \mathrm{cBN}+\mathrm{Li}_{3} \mathrm{~N}$ can be negative or positive when the pressure is between 4.8 and $6.0 \mathrm{GPa}$. It can be obtained from Table 4 that the boundary of negative and positive values forms an approximate $\mathrm{V}$-shaped area (the upper area of curve $\mathrm{A}$ in Figure 1), in which $\Delta G$ of reaction $\mathrm{Li}_{3} \mathrm{BN}_{2} \rightarrow \mathrm{cBN}+\mathrm{Li}_{3} \mathrm{~N}$ is positive and this reaction does not occur. Therefore $\mathrm{Li}_{3} \mathrm{BN}_{2}$ can exist stably, and $\mathrm{cBN}$ does not come from the decomposition of $\mathrm{Li}_{3} \mathrm{BN}_{2}$ in the $\mathrm{V}$-shaped area. Upper area of Curve B in Figure 1 is the V-shaped area from [8] where cBN can grow stably. Figure 1 indicates that the V-shaped area formed in Table 4 covers the most part of the V-shaped area of cBN growth from the references. In other words, the reaction $\mathrm{Li}_{3} \mathrm{BN}_{2} \rightarrow \mathrm{cBN}+\mathrm{Li}_{3} \mathrm{~N}$ cannot occur in the V-shaped area where the macroaggregated and high-quality cBN crystals can be obtained. That is to say, cBN cannot be produced by the treatment of only $\mathrm{Li}_{3} \mathrm{BN}_{2}$ in the $\mathrm{V}$-shaped area 
obtained from Table 4. However, it can be seen from Table 3 that in the same area, $\Delta G$ of the $\mathrm{hBN}-\mathrm{cBN}$ transition is negative, and it becomes more and more negative with increasing temperature and pressure. We speculate that in the $\mathrm{V}$-shaped area, $\mathrm{cBN}$ is probably transformed directly from $\mathrm{hBN}$.

Table 4. $\Delta G$ of $\mathrm{Li}_{3} \mathrm{BN}_{2} \rightarrow \mathrm{cBN}+\mathrm{Li}_{3} \mathrm{~N}$ at different temperatures and pressures.

\begin{tabular}{cccccccc}
\hline \multirow{2}{*}{$\mathbf{T} / \mathbf{K}$} & $\mathbf{4 . 8 ~ G P a}$ & $\mathbf{5 . 0 ~ G P a}$ & $\mathbf{5 . 2 ~ G P a}$ & $\mathbf{5 . 4 ~ G P a}$ & $\mathbf{5 . 6 ~ G P a}$ & $\mathbf{5 . 8 ~ G P a}$ & $\mathbf{6 . 0 ~ G P a}$ \\
\hline 1600 & -3.3405 & -2.4757 & -1.6792 & -0.8553 & -0.0358 & 0.7795 & 1.5904 \\
1650 & -2.4247 & -1.4193 & -0.4822 & 0.4824 & 1.4426 & 2.3984 & 3.3500 \\
1700 & -1.7134 & -0.5583 & 0.5285 & 1.6427 & 2.7525 & 3.8580 & 4.9592 \\
1750 & -1.2296 & 0.0842 & 1.3297 & 2.6026 & 3.8712 & 5.1354 & 6.3953 \\
1800 & -0.9970 & 0.4846 & 1.8979 & 3.3386 & 4.7750 & 6.2070 & 7.6347 \\
1850 & -1.0401 & 0.5865 & 2.2086 & 3.8263 & 5.4395 & 7.0484 & 8.6530 \\
1900 & -1.3837 & 0.4289 & 2.2370 & 4.0406 & 5.8399 & 7.6348 & 9.4254 \\
1950 & -2.0537 & -0.0459 & 1.9573 & 3.9561 & 5.9505 & 7.9405 & 9.9263 \\
2000 & -3.0760 & -0.8640 & 1.3434 & 3.5464 & 5.7451 & 7.9393 & 10.1293 \\
2050 & -4.4774 & -2.0521 & 0.3686 & 2.7849 & 5.1968 & 7.6043 & 10.0076 \\
2100 & -6.2851 & -3.6376 & -0.9945 & 1.6440 & 4.2783 & 6.9081 & 9.5337 \\
2150 & -8.5270 & -5.6482 & -2.7739 & 0.0960 & 2.9615 & 5.8226 & 8.6795 \\
2200 & -11.2312 & -8.1122 & -4.9977 & -1.8877 & 1.2180 & 4.3193 & 7.4164 \\
\hline
\end{tabular}

Figure 1. The $\mathrm{V}$-shaped area of $\Delta G>0$ of $\mathrm{Li}_{3} \mathrm{BN}_{2}$ decomposition and $\mathrm{V}$-shaped area of cBN growth. (A) The $\mathrm{V}$-shaped area of $\Delta G>0$ of $\mathrm{Li}_{3} \mathrm{BN}_{2}$ decomposition. (B) The $\mathrm{V}$-shaped area of cBN growth [3].

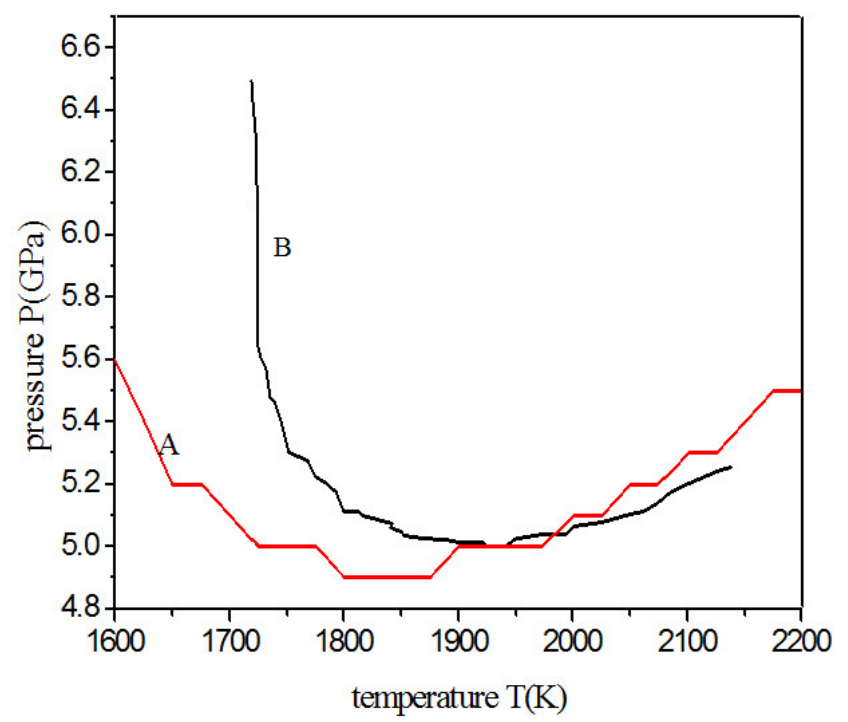

It is known from [2] that cBN does not form when $\mathrm{Li}_{3} \mathrm{BN}_{2}$ melts or decomposes, and only when excess $\mathrm{hBN}$ is added can $\mathrm{cBN}$ be found. $\mathrm{Li}_{3} \mathrm{BN}_{2}$ exists stably in the HPHT area of $\mathrm{cBN}$ growth, and $\mathrm{Li}_{3} \mathrm{BN}_{2}$ appears to be in equilibrium with $\mathrm{cBN}$ in the $\mathrm{Li}_{3} \mathrm{~N}-\mathrm{hBN}$ system. We infer that the catalyst promotes the transition of $\mathrm{hBN}$ to $\mathrm{cBN}$. The melting point of $\mathrm{hBN}$ is over $3000 \mathrm{~K}$ at ambient pressure. $\mathrm{hBN}$ has a stable structure with a $\mathrm{sp}^{2}$ hybridization state in the hexagonal ring layer and Van der Waals' force between layers. The hybridized orbital of $\mathrm{B}$ atom is $\mathrm{sp}^{2}+2 \mathrm{p}^{0}$, and $\mathrm{N}$ atom is $2 \mathrm{~s}^{2}+2 \mathrm{p}^{2}$ in $\mathrm{hBN}$. 
However, the hybridized orbital of $\mathrm{B}$ and $\mathrm{N}$ atom is $\mathrm{sp}^{3}$ in $\mathrm{cBN}$, and the chemical bond between $\mathrm{B}$ and $\mathrm{N}$ atom is a stable $\sigma$-bond, so the most important driving force for the transition from $\mathrm{hBN}$ to $\mathrm{cBN}$ is to transfer an electron from $\mathrm{N}$ atom to $\mathrm{B}$ atom. Part of $\mathrm{Li}^{+}$in the short-range ordered structure of $\mathrm{Li}_{3} \mathrm{BN}_{2}$ absorbs electrons from $\mathrm{N}$ atom at the high active state. Because of its instability, Li cannot exist stably in the high temperature and high pressure system. B atoms with empty orbitals absorb the electrons of $\mathrm{Li}$, and then complete the electronic transfer from $\mathrm{N}$ to $\mathrm{B}$ atoms [21], so both the electrical structures of the $\mathrm{B}$ and $\mathrm{N}$ atoms are $\mathrm{sp}^{2}+2 \mathrm{p}^{1}$. Electrons in the $\mathrm{s}$ orbital of $\mathrm{B}$ and $\mathrm{N}$ atoms at the high temperature are excited into the empty $\mathrm{p}$ orbitals. The $\mathrm{B}$ and $\mathrm{N}$ atom can form a $\mathrm{sp}^{3}$ hybridization state. $\mathrm{B}$ and $\mathrm{N}$ atoms in this $\mathrm{sp}^{3}$ hybridization state form $\sigma$ covalent bonds in a head-to-head mode with energy fluctuations, and generate the microstructure of $\mathrm{cBN}$ at high pressure and high temperature.

$\mathrm{Li}_{3} \mathrm{BN}_{2}$ is short-range ordered at molten-like state under HTHP, and it can be dissolved into well-ordered $\mathrm{hBN} . \mathrm{BN}_{2}{ }^{3-}$ ion invades $\mathrm{hBN}$ and affects the van der Waals forces between the layers, causing inter-layer slippage or breakage. $\mathrm{hBN}$ can be disintegrated into two dimensional B-N dusts with low polymerization degree. At this time, the long-range ordered structure disappears, rendering a short-range ordered structure. Without catalyst, higher temperatures than $3000 \mathrm{~K}$ and higher pressures than $13 \mathrm{GPa}$ are needed to obtain cBN crystals [4]. With the catalyst, a short-range or medium-range ordered molten-like structure [5] forms to greatly reduce the temperature and pressure of $\mathrm{cBN}$ synthesis. From the point of crystal nucleation, the B-N dusts produced by hBN degradation can transform into cBN microstructures by heterogeneous nucleation with energy fluctuation [22]. $\mathrm{Li}_{3} \mathrm{BN}_{2}$ could be the matrix of $\mathrm{cBN}$ nucleation, because of the similar crystal structure and larger lattice constant [23]. The process only forms the microstructure of cBN crystals. In order to obtain cBN crystals, it is essential for the tiny crystal nucleus to grow gradually [24].

\section{Conclusions}

(1) In the HPHT area $(1600 \sim 2200 \mathrm{~K}, 4.8 \sim 6.0 \mathrm{GPa})$ of $\mathrm{cBN}$ growth, the reaction $\mathrm{hBN}+\mathrm{Li}_{3} \mathrm{~N} \rightarrow \mathrm{Li}_{3} \mathrm{BN}_{2}$ can occur, and the $\Delta G$ of the reaction is between -35 and $-10 \mathrm{KJ} \cdot \mathrm{mol}^{-1}$. However, in the same $\mathrm{P}-\mathrm{T}$ area, $\Delta G$ of transition $\mathrm{hBN} \rightarrow \mathrm{CBN}$ is between -25 and $-19 \mathrm{KJ} \cdot \mathrm{mol}^{-1}$, indicating a more probable transition. The $\Delta G$ of decomposition $\mathrm{Li}_{3} \mathrm{BN}_{2} \rightarrow \mathrm{cBN}+\mathrm{Li}_{3} \mathrm{~N}$ is almost positive, thus $\mathrm{Li}_{3} \mathrm{BN}_{2}$ can exist stably.

(2) The area of the positive $\Delta G$ of $\mathrm{Li}_{3} \mathrm{BN}_{2}$ decomposition forms an approximate $\mathrm{V}$-shaped area, which covers the most part of the $\mathrm{V}$-shaped area of cBN crystal growth. Therefore, cBN does not come from the decomposition of $\mathrm{Li}_{3} \mathrm{BN}_{2}$ and $\mathrm{cBN}$ is probably transformed from $\mathrm{hBN}$. However, analysis shows that $\mathrm{Li}_{3} \mathrm{BN}_{2}$ promotes the transfer of an electron from a $\mathrm{N}$ atom to a $\mathrm{B}$ atom in order to form the micro cBN nuclei.

\section{Acknowledgments}

This work is supported by the Natural Science Foundation of China (Grant No. 51272139). 


\section{Author Contributions}

Bin $\mathrm{Xu}$ made substantial contributions to conception and design of this paper. Bin Xu, Mei-Zhe Lv and Hong-Mei Yang performed acquisition, analysis, and interpretation of data. Mei-Zhe Lv and Hong-Mei Yang drafted the paper; Zhen-Xing Wen participated in analysis and interpretation of data, and gave useful suggestions for revising the manuscript; Bin Xu gave final approval of the version to be submitted and any revised version. All authors read and approved the manuscript.

\section{Conflicts of Interest}

The authors declare no conflict of interest.

\section{References}

1. Li, S.; Xu, B.; Guo, X.F.; Wang, H. Fracture morphology and XRD layered characterization of cBN Cake. J. Synth. Cryst. 2012, 41, 15-19, (in Chinese).

2. De Vries, R.C.; Fleischer, J.F. Phase equilibria pertinent to the growth of cubic boron nitride. J. Cryst. Growth 1972, 13, 88-92.

3. Bocquillon, G.; Loriers, G.; Loriers, J. Synthesis of cubic boron nitride using $\mathrm{Mg}$ and pure or M'-doped $\mathrm{Li}_{3} \mathrm{~N}, \mathrm{Ca}_{3} \mathrm{~N}_{2}$ and $\mathrm{Mg}_{3} \mathrm{~N}_{2}$ with $\mathrm{M}^{\prime}=\mathrm{Al}$, B, Si, Ti. J. Mater. Sci. 1993, 28, 3547-3556.

4. Guo, W. Effects of Additive on the Synthesis of High Quality cBN Single Crystal in the $\mathrm{Li}_{3} \mathrm{~N}-\mathrm{hBN}$ System (in Chinese). Ph.D. Thesis, Jilin University, Changchun, China, 2011.

5. Bian, X.F.; Wang, W.M.; Li, H. Metallic Melts Structure (in Chinese); Shanghai Jiao Tong University Press: Shanghai, China, 2003; pp. 66-81.

6. Xu, X.W.; Zhao, H.M.; Fan, H.L.; Li, Y.P. Synthesis of cBN with hBN. J. Univ. Sci. Technol. Beijing 2001, 23, 337-339, (in Chinese).

7. Jia, X.R.; Su, Z.P.; Yang, D.P.; Zhang, T. Direct nucleation and growth of cBN by the chemical reaction. Mater. Lett. 2008, 62, 1721-1723.

8. Xu, B.; Li, L.; Tian, B.; Fan, X.H.; Feng, L.M. Thermodynamic analysis of diamond growth with catalyst at HPHT. Chin. J. High Press. Phys. 2009, 23, 189-195, (in Chinese).

9. Lin, M.X.; Li, Y.H. Thick-grain diamond's growth and ascertainment of its thermodynamic conditions. Chin. J. High Press. Phys. 1994, 8, 36-42, (in Chinese).

10. Ji, X.R. The Effect of hBN Re-crystallized Character on cBN Synthesis and Direct and Growth of cBN (in Chinese). Ph.D. Thesis, Jilin University, Changchun, China, 2008.

11. Niu, Z.; Xu, B.; Tian, B.; Fan, X.H. Characterization on the diamond/metallic catalyst interface and thermodynamic analysis of the diamond crystal growth. J. Synth. Cryst. 2010, 39, 1367-1380, (in Chinese).

12. Liang, Y.J.; Che, Y.C. ; Liu, X.X.; Li N J. Thermodynamical Data of Inorganic Substancep (in Chinese); Northeastern University Press: Shenyang, China, 1993; p. 214.

13. Kuhr, M.; Ke, S.R.; Kulisch, W. Nucleation of cubic boron nitride (c-BN) with ion-induced plasma-enhanced CVD. Int. J. Refract. Met. Hard Mater. 1996, 14, 145-157.

14. Siegel, D.J.; Wolverton, C.; Ozolinšs, V. Reaction energetics and crystal structure of $\mathrm{Li}_{4} \mathrm{BN}_{3} \mathrm{H}_{10}$ from first principles. Phys. Rev. B 2007, 75, 014101. 
15. Sung, J. Graphite $\rightarrow$ diamond transition under high pressure: A kinetics approach. J. Mater. Sci. 2000, 35, 6041-6054.

16. Guo, Y.D. Research in Elastic and Thermodynamic Properties for $\mathrm{MgO}, \mathrm{cBN}$ and other Crystals Under High Pressure (in Chinese). Ph.D. Thesis, Sichuan University, Chengdu, China, 2007.

17. Solozhenko, V.L.; Turkevich, V.Z. High pressure phase equilibria in the $\mathrm{Li}_{3} \mathrm{~N}-\mathrm{BN}$ system: In situ studies. Mater. Lett. 1997, 32, 179-184.

18. Hossain, M.; Islam, A.K.M.A.; Islam, F. Elastic Properties of $\alpha$-and $\beta$-phases of $\mathrm{Li}_{3}$ N. J. Sci. Res. 2009, 1, 182-191.

19. Edgar, J.H., Ed. Properties of Group III Nitrides; EMIS Datareviews Series No. 11; INSPEC, The Institution of Electrical Engineers: London, UK, 1994; pp. 14-15.

20. Huq, A.; Richardson, J.W.; Maxey, E.R.; Chandra, D.; Chien, W.-M. Structural studies of $\mathrm{Li}_{3} \mathrm{~N}$ using neutron powder diffraction. J. Alloys Compd. 2007, 436, 256-260.

21. Lu, Z.T. Conversion and inverse transformation of diamond and cubic boron nitride with catalyst. Diam. Abras. Eng. 1981, 3, 5-11, (in Chinese).

22. Wang, C.X. Nucleation thermodynamics of cubic boron nitride upon high-pressure and high-temperature supercritical fluid system in nanoscale. J. Phys. Chem. B 2004, 108, 728-731.

23. Yamane, H.; Kikkawa, S.; Koizumi, M. High-and low-temperature phases of lithium boron nitride, $\mathrm{Li}_{3} \mathrm{BN}_{2}$ : Preparation, phase relation, crystal structure, and ionic conductivity. J. Solid State Chem. 1987, 71, 1-11.

24. Guo, X.F.; Xu, B.; Yang, H.M.; Wen, Z.X.; Fan, X.H.; Tian, B. Research on growth interface morphology and phase structures of cBN. J. Synth. Cryst. 2012, 41, 1538-1542, (in Chinese).

(C) 2014 by the authors; licensee MDPI, Basel, Switzerland. This article is an open access article distributed under the terms and conditions of the Creative Commons Attribution license (http://creativecommons.org/licenses/by/3.0/). 